\title{
Non-invasive mechanical ventilation in internal medicine departments: a pilot study
}

\author{
Micaela La Regina, Alessia Marinaro, Lucia Scuotri, Francesca Corsini, Francesco Orlandini \\ SC Medicina Interna, Presidio Ospedaliero Unico del Levante Ligure, Stab. S. Andrea, ASL 5 Liguria, La Spezia, Italy
}

\begin{abstract}
Non-invasive mechanical ventilation (NIMV) has been shown to be an effective treatment in chronic and acute lung failure. Until a few years ago, all the different forms of mechanical ventilation were managed exclusively in intensive care units (ICU). However, the reduction in the number of ICU beds available and the high costs involved in running such units, together with the aging of the general population and the co-morbidities associated with this have meant that forms of mechanical ventilation are also used outside ICUs. In addition to emergency physicians and pneumologists, also internists have started to use NIMV on their wards in order to start treatment as early as possible and reduce costs. This is a preliminary study to explore the effectiveness, safety and feasibility of NIMV on a medical ward. The overall success rate was $68.8 \%$; the likelihood of success was higher in patients who started NIMV earlier. The success rate was quite high (62\%) also among do-not-intubate patients, despite their poorer clinical condition. Few complications were reported and there was no increase in staff workload. No significant differences were found in in-hospital mortality between hypercapnic patients with chronic obstructive pulmonary disease (COPD) exacerbation and hypercapnic patients with COPD plus pneumonia $(27 \% v s 25 \%)$ or between patients with pneumonia and patients with COPD plus pneumonia (26\% vs 25\%). These results are encouraging for the successful use of NIMV on medical wards. A careful selection of patients, educating and motivating staff in NIMV use, and close collaboration with resuscitators are all essential for this to be achieved.
\end{abstract}

Correspondence: Micaela La Regina, SC Medicina Interna, Presidio Ospedaliero Unico del Levante Ligure, Stab. S. Andrea, ASL 5 Liguria, Scalinata Fondega 12, 19121 La Spezia, Italy.

Tel. +39.338.2393805 - Fax. +39.0187.533483.

E-mail: micaela.laregina@rm.unicatt.it

Key words: acute respiratory failure, non-invasive mechanical ventilation, internal medicine department, medical wards, chronic obstructive pulmonary disease.

Acknowledgments: we thank Medicair for providing ventilators, circuits and masks and practical support. We also thank Loriana Arbasetti, Ilaria Bandini, Leontina Berti, Rosalba De Simone, Loredana Donzè, Cristina Facchini, Mara Ferrari, Giovanna Figoli, Mariangela Lo Nigro, Michela Maldini, Nadia Ortu, Sonia Palagi, Raffaele Valletta, Monica Farina, Tiziana Paita and Angela Coluccini for their dedication to work and their patients, and for being open to learning new skills.

Conflict of interests: the authors declare no potential conflict of interests.

This work is licensed under a Creative Commons Attribution NonCommercial 3.0 License (CC BY-NC 3.0).

CCopyright M. La Regina et al., 2013

Licensee PAGEPress, Italy

Italian Journal of Medicine 2013; 7:172-178

doi:10.4081/itjm.2013.172

\section{Introduction}

In the last decades, significant advances have been made in the treatment of chronic respiratory failure and acute respiratory failure (ARF) after the introduction of non-invasive mechanical ventilation (NIMV). This allows the delivery of a positive pressure ventilation by a tightly fitting nasal or oro-facial mask or a helmet instead of an artificial airway, such as an endotracheal or tracheostomy tube. ${ }^{1,2}$ The same positive pressure can be applied constantly during the respiratory cycle (c-PAP mode) or different positive pressures can be delivered during inspiration and expiration (bPAP mode). Prospective randomized controlled trials have repeatedly demonstrated that it is effective in hypoxemic and hypercapnic respiratory failure due to reexacerbation of chronic obstructive pulmonary disease (COPD) and hypoxemic respiratory failure caused by pnuemonia or cardiogenic edema. ${ }^{3-5}$ In chronic settings, NIMV is effective in obstructive sleep apnea syndrome, restrictive lung diseases and neuromuscular diseases. ${ }^{6}$ Furthermore, this technique can be used in post-operative patients, as palliative treatment of symptoms in terminally ill patients, or to help with bronchoscopy. ${ }^{7}$

Until some years ago, all the different forms of mechanical ventilation were managed exclusively by intensive care unit (ICU) staff. However, the reduction in the number of ICU beds available and the high costs involved in running such units, together with the aging of 
the general population and the co-morbidities associated with this have meant that forms of mechanical ventilation are also used outside ICUs. In addition to emergency physicians and pneumologists, more recently also internists have started to use NIMV on their wards with the advantage of treating more patients, treating them earlier and reducing costs. ${ }^{8}$ The advantages include the possibility of delaying endotracheal intubation that can cause further lung and mental deterioration, heart failure, and aspiration problems. ${ }^{9} \mathrm{~A}$ British survey showed that while in $1998-99$ over $75 \%$ of NIMV treatments were delivered in ICUs, in 2000$0171 \%$ were delivered on medical wards..$^{10}$ In 2006 , Balami et al. reported their successful experience in 36 COPD patients admitted to a medical unit ${ }^{11}$ and Fiorino et al. reported on 27 COPD patients admitted to an Italian General Medical ward with a median nurse:patient ratio of 1:12. ${ }^{12}$ In 2000, a multicenter randomized controlled trial by Plant et al. reported a rapid improvement in respiratory parameters, and reduction in the need for intubation and in-hospital mortality on 25 medical/respiratory wards without previous experience in NIMV and a mean nurse:patient ratio of $1: 11 .{ }^{13}$ Finally, in 2005, the Collaborative Research Group of Non-invasive Mechanical Ventilation for Chronic Obstructive Pulmonary Disease provided a multicenter randomized controlled study on 342 patients that showed NIMV can be used as a routine treatment for acute exacerbation of COPD on general medicine wards. ${ }^{14}$

This is a prospective pilot study to explore effectiveness, safety and feasibility of NIMV on a medical ward equipped with 52 beds, 9 non-expert and one expert physicians, and a nurse:patient ratio of 1:13.

\section{Materials and Methods}

The hospital is equipped with 5 intensive care beds, 11 beds in a high dependency unit of the Accident and Emergency Department, and 52 beds for acute medical care on our ward where there are 10 physicians and 22 nurses. An internist is on call $24 \mathrm{~h}$ a day. The nurse:patient ratio is 1:13 on all shifts. The selection of patients admitted to intensive care is very rigorous because of the small number of beds. High dependency unit staff uses exclusively c-PAP.

For this study, from February 2009 to September 2011 we enrolled all the patients admitted on our ward for ARF who satisfied the following inclusion criteria: i) hypoxemic $\mathrm{ARF}$ associated with hypoxemia $\left(\mathrm{pO}_{2}<60\right.$ $\mathrm{mmHg}$, normal $\mathrm{pCO}_{2}$ or hypocapnia, $\mathrm{pH}>7.35$ ) and/or respiratory distress in spite of ceiling treatment; or ii) hypercapnic $\left(\mathrm{pCO}_{2}>50 \mathrm{mmHg}\right) \mathrm{ARF}$ associated with $\mathrm{pH}<7.35$ and two or more of the following: clinical signs of respiratory distress, respiratory rate $>25 / \mathrm{min}$, $\mathrm{SO}_{2}<88 \%$ in $\mathrm{O}_{2} 31 / \mathrm{min}$, sudden increase in $\mathrm{pCO}_{2}$ of 15 $20 \mathrm{mmHg}$, abnormal sensory response.
We excluded patients with serious ischemia or ventricular arrhythmias on electrocardiogram, coma, facial trauma, pneumothorax/pneumomediastinum, secretions/vomiting, endotracheal intubation need.

We used Medicair vivo 30 (BREAS Medical AB, Mölnlycke, Sweden) as ventilator with orofacial masks of different sizes and models according to patients' preferences. Monitoring was carried out according to the protocol used outside the ICU by Cabrini et $a l .{ }^{14}$ Relatives were asked to immediately request the presence of medical and nursing staff if they noticed any potential change in the clinical status of ventilated patients. All the staff had been formally trained in the delivery of NIMV and an easy-use protocol was available. A hemogas-analyzer was present on the ward.

We reported clinical and laboratory parameters for the treatment period in pre-established forms. They included: blood gases, vital parameters and consciousness evaluation according to the Kelly scale before starting the treatment and at any re-evaluation, pressures and oxygen flow delivered at each step.

In hypercapnic patients, NIMV protocol consisted in setting inspiratory positive airway pressure and expiratory positive airway pressure (EPAP) at low levels, i.e. $10 / 4$ or $12 / 5 \mathrm{~cm} \mathrm{H}_{2} \mathrm{O}$, and an oxygen flow $\left(\mathrm{FiO}_{2}\right)$ able to reach a peripheral saturation, $\mathrm{spO}_{2}$, of $88-92 \%$ at the beginning of the procedure, then in increasing pressure support up to obtain a tidal volume of approximately $6 \mathrm{~mL} / \mathrm{kg}$, a respiratory rate of less than 25 breaths/min, and maintain patient comfort. EPAP was increased to counterbalance intrinsic positive end expiratory pressure and improve inspiratory triggering. In hypoxemic patients, c-PAP was initially set at 5-7.5 $\mathrm{cm} \mathrm{H}_{2} \mathrm{O}$ and $\mathrm{O}_{2}$ was gradually increased to obtain a hemoglobin saturation of between $94-98 \% .^{15}$

In this population, we evaluated outcomes of effectiveness and tolerability such as response rate, mean time to success, intolerance rate, failure rate, need for intubation, and in-hospital mortality. Response rate was evaluated as responsive if the patient satisfied response criteria within $2 \mathrm{~h}$ of treatment. Response rate criteria are shown in Table 1.

Criteria for intubation were derived from those used by Brochard et al. ${ }^{9}$ and agreed after discussion with the intensive care physicians. Patients were considered to need intubation if they met any of the following criteria (unless they had a do-not-intubate order): i) $\mathrm{pH}$ below 7.20; ii) $\mathrm{pH} 7.20-7.25$ on two occasions $1 \mathrm{~h}$ apart; iii) hypercapnic coma (Glasgow coma scale $<8$ and $\mathrm{PaCO}_{2}>80 \mathrm{mmHg}$ ); iv) $\mathrm{PaO}_{2}$ below $60 \mathrm{mmHg}$ despite maximum tolerated $\mathrm{FiO}_{2}$; and v) cardiorespiratory arrest.

In case of NIMV failure, patients without a do-notintubate order were referred to ICU. We considered do-not-intubate patients (DNI-patients) to be those of advanced age, bed-ridden, with severe cognitive im- 
pairment, and/or severe and multiple comorbidities, and/or short life expectancy.

We also evaluated safety and feasibility outcomes in order to assess the application of NIMV in internal medicine. We calculated the rate of complications, mean duration of treatment and mean number of clinical/ laboratory examinations to estimate the staff workload.

In a subgroup of hypercapnic patients who were able to specify the time of symptom onset, we also evaluated the time from symptom onset to starting NIMV in order to correlate the time to success. Results are given as percentages and means. The survival rate method was applied to study the relation between time of symptom onset and success rate.

A subgroup analysis comparing hypercapnic patients with $\mathrm{pH}<7.25$ and $\geq 7.25$ was performed; $2 \times 2$ tables were analyzed by Fisher's exact test.

\section{Results}

In 33 months, we collected data on 147 patients ( 75 men, 72 women; mean age 82, range $47-96$ years). Sixty-nine percent suffered from hypercapnic ARF (66\% due to exacerbation of COPD, 30\% heart failure, $3 \%$ lung cancer and $1 \%$ hepatopulmonary syndrome) and $31 \%$ from hypoxemic ARF (50\% due to cardiogenic edema and 50\% pneumonia). COPD diagnosis was mainly based on clinical criteria, only a small number of patients have spirometric data. ${ }^{10}$ In $64 \%$ of cases, alertness was evaluated according to Kelly's scale at 34 and all patients had more than two comorbidities.

Pre-treatment hemogas-analytic parameters were, on average: $\mathrm{pH}=7.30$ (range 7.13-7.52), $\mathrm{pO}_{2}=39$ $\mathrm{mmHg}$ (range 24-114), $\mathrm{pCO}_{2}=52 \mathrm{mmHg}(29-101)$, $\mathrm{PaO}_{2} / \mathrm{FiO}_{2}=185$ (range 64-457).

Seventy percent of study subjects were treated by b-PAP and $30 \%$ by c-PAP; $20 \%$ of them shifted from c-PAP to b-PAP because of an unsuccessful c-PAP. Patients' characteristics, basal blood gas values and study outcomes according to type of ARF and etiology are shown in Figure 1 and Table 2.

In our series, $6 \%$ of patients were intolerant to noninvasive ventilation, so they were excluded from the subsequent analysis. The success rate (Table 1) was $68.8 \%(68.5 \%$ in the group of hypercapnic patients and $69.5 \%$ in the hypoxiemic group); the failure rate was $31.9 \%$. Among non-responsive patients, $4 \%$ were intubated, while the others had a do-not-intubate order. In-hospital mortality was $27.6 \%$. In our experience, NIMV was a safe procedure with a small incidence of complications $(11.3 \%$ of patients: $1.3 \%$

Table 1. Response criteria.

\begin{tabular}{lc}
\hline Hypoxemic ARF & Stable correction of hypoxia+increase of more than 100 units of $\mathrm{PaO}_{2} / \mathrm{FiO}_{2}$ after $2 \mathrm{~h}$ \\
\hline Hypoxemic and hypercapnic ARF & More than $20 \% \mathrm{pCO}_{2}$ reduction and $\mathrm{pH}$ improvement after $2 \mathrm{~h}$ \\
Alertness recovery \\
Respiratory distress recovery
\end{tabular}

ARF, acute respiratory failure.

Table 2. Population characteristics at non-invasive mechanical ventilation (NIMV) initiation for overall population and 3 NIMV group.

\begin{tabular}{|c|c|c|c|c|c|}
\hline Parameters & $\begin{array}{c}\text { Overall population } \\
n=147\end{array}$ & $\begin{array}{c}\text { Group 1 } \\
\text { Hypoxemic ARF } \\
\text { (heart failure) } n=23\end{array}$ & $\begin{array}{c}\text { Group } 2 \\
\text { Hypoxemic ARF } \\
\text { (pneumonia) } n=23\end{array}$ & $\begin{array}{c}\text { Group } 3 \\
\text { Hypercapnic ARF } \\
\text { n=101 }\end{array}$ & $\begin{array}{c}P \\
1 \text { vs } 2 \\
1+2 \text { vs } 3\end{array}$ \\
\hline Age, years (range) & $82 \pm 7.3(47-96)$ & $83.3 \pm 7.68(67-94)$ & $76 \pm 13.24$ (49-96) & $87.7 \pm 7(47-96)$ & $\begin{array}{l}0.0318 \\
\mathrm{NS}\end{array}$ \\
\hline Gender (M/F\%) & $75 / 72(51 / 49 \%)$ & $12 / 11(53 / 47 \%)$ & $13 / 10(56 / 44 \%)$ & $50 / 51(49.5 / 50.5 \%)$ & $\begin{array}{l}\text { NS } \\
\text { NS }\end{array}$ \\
\hline $\mathrm{pH}$ mean & $7.30 \pm 0.09$ & $7.46 \pm 0.03$ & $7.38 \pm 0.12$ & $7.26 \pm 0.1$ & $\begin{array}{c}\mathrm{NS} \\
0.0004\end{array}$ \\
\hline $\mathrm{pO}_{2}$ & $53 \pm 16.4$ & $37 \pm 10.4$ & $46 \pm 10.4$ & $55.4 \pm 17$ & $\begin{array}{l}\text { NS } \\
\text { NS }\end{array}$ \\
\hline $\mathrm{pCO}_{2}$ & $70 \pm 19.6$ & $30 \pm 12$ & $42 \pm 16$ & $76 \pm 14.2$ & $\begin{array}{c}\mathrm{NS} \\
0.0001\end{array}$ \\
\hline $\mathrm{pO}_{2} / \mathrm{FiO}_{2}$ & 220 & 179 & 218 & 260 & $\begin{array}{l}\text { NS } \\
\text { NS }\end{array}$ \\
\hline
\end{tabular}

ARF, acute respiratory failure; NS, not significant. 
hypotension, $10 \%$ pressure sites on the face).

We found no significant differences in terms of inhospital mortality between hypercapnic patients with COPD exacerbation and hypercapnic patients with COPD plus pneumonia ( $27 \%$ vs $25 \%$ ) or between patients with pneumonia and patients with COPD plus pneumonia (26\% vs 25\%). Details about arterial blood gas values of patients who have been discharged alive are shown in Table 3. Mean values of arterial blood gases at admission, after $2 \mathrm{~h}$ of NIMV and at discharge for COPD patients discharged alive showed a progressive improvement in arterial $\mathrm{pH}$ and $\mathrm{PaCO}_{2}$; a quick improvement in acidosis was recorded after $2 \mathrm{~h}$ of NIMV, with stable and significant improvement in $\mathrm{pH}$, confirmed by further measurements at discharge.

Patients with COPD and pneumonia (actually only a small number) improved more slowly but more significantly than patients with COPD exacerbation with- out pneumonia ( $\mathrm{pH}$ at $2 \mathrm{~h}: 7.28$ vs 7.37; $\mathrm{pH}$ at discharge 7.38 vs $7.40 ; \mathrm{pCO}_{2}$ at $2 \mathrm{~h} 70.2$ vs $62.8 \mathrm{mmHg}$; $\mathrm{pCO}_{2}$ at discharge 52.7 vs $61.2 \mathrm{mmHg}$ ).

Patients with pneumonia and without COPD had a good trend toward improvement in our series.

The rate of late failure in patients treated by NIMV for COPD exacerbation was $20 \%$, similar to previous reports. ${ }^{11}$

The treatment did not cause an increase in working load of physicians or nurses. The mean number of clinical and hemogas-analytical examinations was 8 and 13 , respectively. If one correlates these findings to the mean duration of treatment (4.4 days), it is equal to less than 2 clinical examinations a day and less than 3 hemogas-analyses a day, one for any nursing shift.

The relation between time of symptom onset and success, analyzed by the survival rates method in a subgroup of 31 hypercapnic patients, showed that an

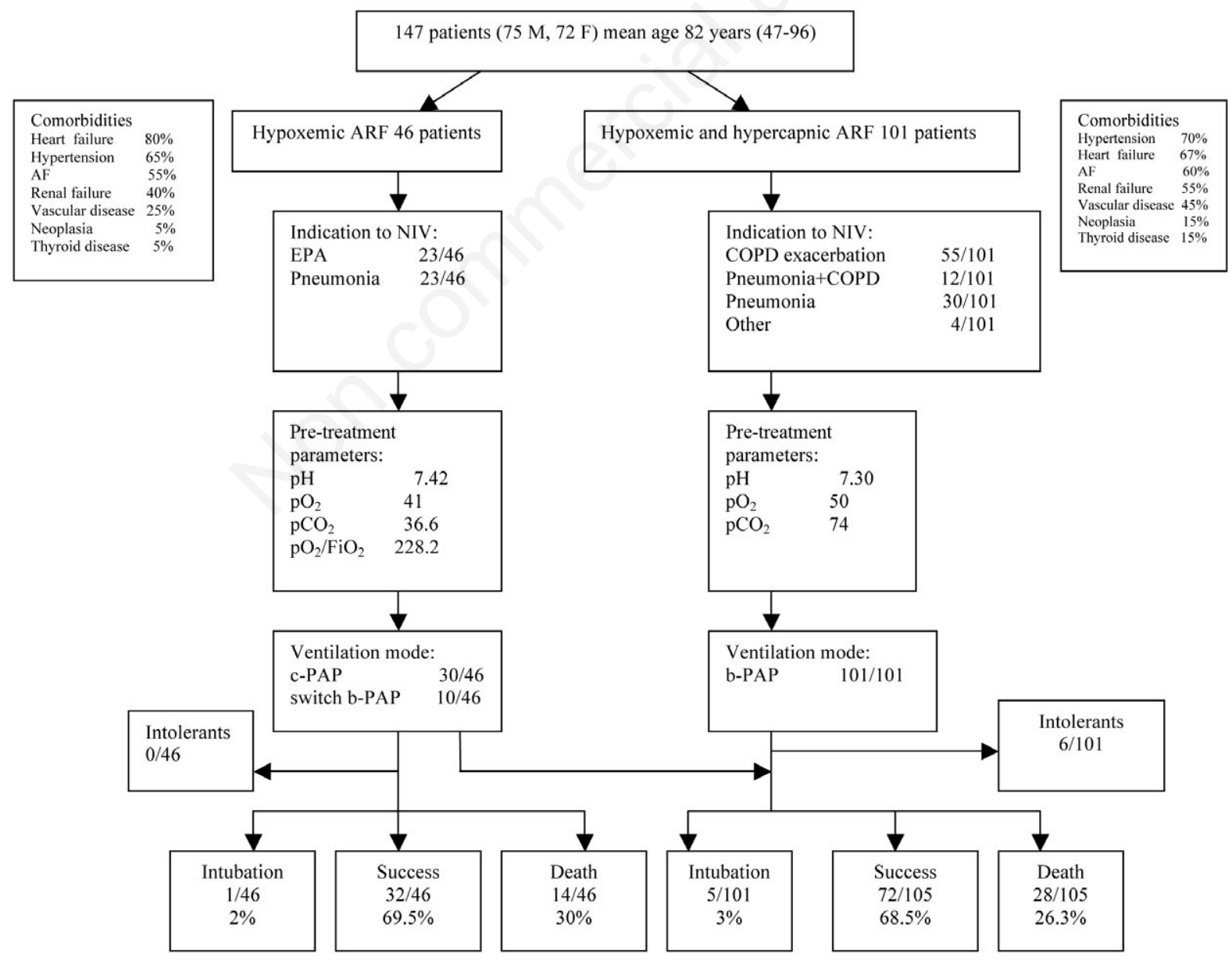

Figure 1. Flow-chart of patients' characteristics and study outcomes. AF, atrial fibrillation; ARF, acute respiratory failure; NIV, non-invasive ventilation; EPA, expiratory positive airway; COPD, chronic obstructive pulmonary disease. 
earlier intervention is more likely to achieve success and $90 \mathrm{~min}$ is the time after which the number of failures overcomes the number of successes.

The percentage of DNI-patients was high in our study at $60 \%$. After we excluded the intolerant patients $(6 \%)$, the success rate in this group was almost equivalent to that of the total study population $(62 \% v s$ $68.8 \%$ ), despite the most advanced age and the several comorbidities that justified the DNI code.

Finally, we compared more severe hypercapnic patients with $\mathrm{pH}<7.25$ and less severe ones with $\mathrm{pH} \geq 7.25$ (Table 4). We did not find any statistically significant difference between the two groups in terms of success, complication rate or in-hospital mortality.

\section{Discussion and Conclusions}

This is the largest report on the use of NIMV by internists on a standard medical ward of a non-teaching hospital. The results suggest that NIMV can be effective, feasible and safe in this setting and b-PAP is the most applied mode.

The advantages of treating ARF patients by NIMV in a medical ward are several and conspicuous. First of all, the treatment starts earlier: an early intervention increases the likelihood of success, ${ }^{16}$ and reduces the percentage of intubations and related complications, such as nosocomial infections, injury of the vocal cord or trachea, aspiration of gastric content, irritation or injury due to the endotracheal tube, edema, inflammation and increased mucus production). ${ }^{1}$ Second, it reduces expensive admissions in intensive care units, resulting in a greater availability of ICU beds for other categories of patients (who would not otherwise be manageable), shorter hospital stays and lower costs. ${ }^{4}$ So, it is highly desirable both for patients and for health administrations.
The fear that NIMV can be dangerous and harmful in an inadequate setting is a justified objection. However, patients outside intensive care units are at an earlier stage of ARF, so they do not require such a high intensity of care that is inconsistent with medical wards.

Obviously, medical, nursing and technical staff must be adequately trained to use NIMV and the necessary equipment must be available. Two preliminary meetings about ventilators, masks and monitoring, and on-the-job training were held to educate our staff.

Even if our ward is a standard medical ward, not equipped with remote-monitoring systems, we did not report any serious NIMV-related complication, such as hypotension or regurgitation. We believe that the participation of a motivated and skilled staff, an accurate selection of patients, and also the involvement of the patient's family are all crucial for good results to be reached. Also, close collaboration with resuscitators, as in our case, is essential to avoid undesirable delayed intubations in case of NIMV failure.

We were aware of the risk of appearing to force staff to carry out repeated clinical evaluations of patients and there was the strong fear that this could increase staff workload. However, we saw that controls were more frequent only in the first hours of treatment, when staff titrate the ventilator parameters and oxygen. With regards to the mean duration of treatment, this approach involves only one blood gas test for each nursing shift and less than one clinical evaluation for each medical shift. However, we compared our series to a historical group of ARF patients treated with conventional therapy some years before in our ward and the staff workload was similar. The mean number of clinical and hemogas-analytical examinations in this population was 7.5 and 11 , respectively.

If we exclude the randomized controlled trials conducted by Plant et al. ${ }^{16}$ and by the Collaborative Research Group of Non-invasive Mechanical Ventilation

Table 3. Comparison between blood gas values in patients with chronic obstructive pulmonary disease (COPD) exacerbation, COPD plus pneumonia or pneumonia alone, treated by non-invasive mechanical ventilation.

\begin{tabular}{|c|c|c|c|c|c|c|c|c|c|c|}
\hline & \multirow[t]{2}{*}{$\begin{array}{c}\text { No. } \\
\text { of patients }\end{array}$} & \multicolumn{3}{|c|}{$\begin{array}{l}\text { Mean value of blood } \\
\text { gases at admission }\end{array}$} & \multicolumn{3}{|c|}{$\begin{array}{l}\text { Mean value of blood } \\
\text { gases after } 2 \text { h of NIMV }\end{array}$} & \multicolumn{3}{|c|}{$\begin{array}{l}\text { Mean value of blood } \\
\text { gases at discharge }\end{array}$} \\
\hline & & $\mathbf{p H}$ & $\mathrm{pO}_{2}$ & $\mathrm{pCO}_{2}$ & pH & $\mathrm{pO}_{2}$ & $\mathrm{pCO}_{2}$ & $\mathbf{p H}$ & $\mathrm{pO}_{2}$ & $\mathrm{pCO}_{2}$ \\
\hline $\begin{array}{l}\text { COPD } \\
\text { exacerbation }\end{array}$ & 55 & $7.29 \pm 0.05$ & $56 \pm 18.6$ & $74.7 \pm 13.4$ & $\begin{array}{l}7.37 \pm 0.05 \\
+11 \%\end{array}$ & $\begin{array}{c}66.7 \pm 13.2 \\
+18 \%\end{array}$ & $\begin{array}{c}62.8 \pm 11.8 \\
-16 \%\end{array}$ & $\begin{array}{l}7.38 \pm 0.03 \\
+12 \%\end{array}$ & $\begin{array}{l}65.4 \pm 11.6 \\
+16 \%\end{array}$ & $\begin{array}{c}61.2 \pm 14.5 \\
-18 \%\end{array}$ \\
\hline $\begin{array}{l}\text { COPD } \\
+ \text { pneumonia }\end{array}$ & 12 & $7.24 \pm 0.05$ & $53 \pm 8.3$ & $76 \pm 13$ & $\begin{array}{c}7.28 \pm 0.07 \\
+5 \%\end{array}$ & $\begin{array}{l}60 \pm 28 \\
+13 \%\end{array}$ & $\begin{array}{c}70.2 \pm 14.2 \\
-8 \%\end{array}$ & $\begin{array}{l}7.40 \pm 0.01 \\
+22 \%\end{array}$ & $\begin{array}{c}76 \pm 17.2 \\
+49 \%\end{array}$ & $\begin{array}{c}52.7 \pm 10.4 \\
-30 \%\end{array}$ \\
\hline Pneumonia & 56 & $7.38 \pm 0.12$ & $46 \pm 9.9$ & $50.6 \pm 22$ & $\begin{array}{c}7.45 \pm 0.05 \\
+8 \%\end{array}$ & $\begin{array}{l}70.5 \pm 8.9 \\
+53 \%\end{array}$ & $\begin{array}{c}45.4 \pm 10.1 \\
-10 \%\end{array}$ & $\begin{array}{l}7.44 \pm 0.04 \\
+8 \%\end{array}$ & $\begin{array}{l}75.4 \pm 14.8 \\
+64 \%\end{array}$ & $\begin{array}{l}40 \pm 7 \\
-21 \%\end{array}$ \\
\hline $\begin{array}{l}\mathrm{P} \\
\text { in comparison } \\
\text { to admission }\end{array}$ & & & & & $\begin{array}{l}0.0001 \\
0.2423 \\
0.1411\end{array}$ & $\begin{array}{l}0.0067 \\
0.5524 \\
0.0001\end{array}$ & $\begin{array}{l}0.0017 \\
0.5309 \\
0.5108\end{array}$ & $\begin{array}{l}0.0001 \\
0.0001 \\
0.1518\end{array}$ & $\begin{array}{l}0.0069 \\
0.0115 \\
0.0001\end{array}$ & $\begin{array}{l}0.0022 \\
0.0124 \\
0.5822\end{array}$ \\
\hline
\end{tabular}

NIMV, non-invasive mechanical ventilation; COPD, chronic obstructive pulmonary disease. 
for Chronic Obstructive Pulmonary Disease, ${ }^{17}$ and the study by Cabrini et al. ${ }^{18}$ performed outside the ICU (and also in General Medicine) by a medical emergency team and not by internists, to our knowledge there are only two other smaller studies performed on medical wards to which we can compare our data. ${ }^{13,14}$ Our results are not very different from those of studies performed outside ICU and respiratory wards: we reported a success rate of $68.8 \%$ vs $60.5 \%$ reported by Antro et $a l$. in a high dependency unit, ${ }^{2}$ and $69 \%$ by Cabrini et $a l$. in a General Medicine Department. ${ }^{18}$ It is worthy of note that our population includes a larger proportion of DNI-patients and these patients with a poorer clinical condition will have had an obvious impact on success rate. In-hospital mortality registered in our series was $27.6 \%$ versus $27.4 \%$ reported by Antro et al., ${ }^{2}$ while Cabrini et al. ${ }^{14}$ did not report the mortality rate in the General Medicine cohort. So the lack of detailed data on mortality, the percentage of DNI-patients, and the use of different comorbidity scales do not allow us to make a more detailed comparison. Balami et al. ${ }^{13}$ reported a higher success rate $(79 \%)$, but mean age was considerably higher in our series and it is well known that age is the main factor affecting NIMV success. ${ }^{19}$

Fiorino et al..$^{14}$ do not report the success rate. However, in terms of improvement of arterial blood gases, we found a slower improvement in our COPD patients.

A previous observation that an early intervention provides better outcomes in terms of improvement of physiological variables and need for intubation ${ }^{16}$ was confirmed also in our study in terms of success rate. The relation between the time of symptom onset and the rate of success, analyzed by the survival rates method in a subgroup of hypercapnic patients, showed that $90 \mathrm{~min}$ is the maximum allowed time after which the failures outnumber the successes. It is questionable whether the patients always arrive on the wards from Accident and Emergency Departments within $1.5 \mathrm{~h}$ from symptom onset, so our suggestion is to start the treatment as soon as possible, in the Accident and Emergency Department, and then refer the patients to wards able to assure a continuum of care.
In the group of DNI-patients, our results confirmed previous reports about the success of NIMV in elderly patients with acute hypercapnic ARF.,20 The difference between the success rate in the DNI-patients and the remaining study population is not statistically significant (62\% vs 68.8\%), so that being a DNI-patient seems not to affect the response to treatment if it is early and adequate. This is an exclusive finding from hands on clinical experience as this category of patients are not enrolled in randomized controlled trials, and it supports the unique role of NIMV in patients who are not candidates for intubation.

As the subgroup analysis comparing more and less serious ( $\mathrm{pH}<7.25$ vs $\mathrm{pH} \geq 7.25)$ hypercapnic patients did not reveal any statistically significant difference among the two groups, neither in terms of in-hospital mortality, we can speculate that NIMV provided added benefit in more compromised patients, making their outcome similar to the rest of the study cohort. Nevertheless, our data confirm those of Balami et al. ${ }^{13}$ and Fiorino et al. ${ }^{14}$ who have already reported no difference in terms of baseline $\mathrm{pH}$ among patients who died in hospital.

We are aware that our findings are subject to several limitations: i) it is a pilot study; ii) there is no long-term follow up; iii) there is no comparative group; iv) COPD diagnosis is mainly based on clinical criteria (spirometric data were available in only a small percentage of patients). However, these results can encourage the more widespread use of NIMV on standard medical wards, giving as they do reassurances mainly about feasibility and safety, and supporting randomized controlled studies in this setting in the future.

\section{References}

1. Mehta S, Hill NS. Non-invasive ventilation. Am J Respir Crit Care Med 2001;163:540-77.

2. Antro C, Merico F, Urbino R, Gai V. Non-invasive ventilation as a first-line treatment for acute respiratory failure: real life experience in the emergency department. Emerg Med J 2005;22:772-7.

3. British Thoracic Society Standards of Care Commit-

Table 4. Comparison between patients with $\mathrm{pH}<7.25$ and patients with $\mathrm{pH} \geq 7.25$.

\begin{tabular}{lccc}
\hline & $\mathbf{p H}<\mathbf{7 . 2 5}$ & $\mathbf{p H} \geq \mathbf{7 . 2 5}$ & $\mathbf{P}$ \\
\hline Sample size, no. (\%) & $40(39.6)$ & $61(60.4)$ & 86.3 \\
\hline Mean age, years & 83.6 & $39(54)$ & 1.00 \\
\hline Responses, no. (\%) & $22(56)$ & $2(2.8)$ & 0.3489 \\
\hline Intubations, no. (\%) & $3(7.5)$ & 5.1 & \\
\hline Mean duration of treatment (days) & 2.9 & $9-13$ & $15(21.1)$ \\
\hline Mean number of clinical-hemogas-analytical examinations & $6-10$ & 0.2548 \\
\hline Deaths, no. (\%) & $13(32.5)$ & & \\
\hline
\end{tabular}


tee. Non-invasive ventilation in acute respiratory failure. Thorax 2002;57:192-211.

4. Evans TW. International Consensus Conferences in Intensive Care Medicine: non-invasive positive pressure ventilation in acute respiratory failure. Organised jointly by the American Thoracic Society, the European Respiratory Society, the European Society of Intensive Care Medicine, and the Société de Réanimation de Langue Française, and approved by the ATS Board of Directors. Intensive Care Med 2001;27:166-78.

5. Liesching T, Kwok H, Hill NS. Acute applications of noninvasive positive pressure ventilation. Chest 2003; 124:699-713

6. Meyer TJ, Hill NS. Noninvasive positive pressure ventilation to treat respiratory failure. Ann Intern Med 1994;120:760-70.

7. Nava S, Hill N. Non-invasive ventilation in acute respiratory failure. Lancet 2009;374:250-9.

8. Badiger R, Green M, Hackwood H, et al. Non-invasive ventilation in surgical patients in a district general hospital. Anesthesia 2004;59:967-70.

9. Brochard L, Mancebo J, Wysocki M, et al. Noninvasive ventilation for acute exacerbations of chronic obstructive pulmonary disease. N Engl J Med 1995;333: 817-22.

10. Moretti M, Cilione C, Tampieri A, et al. Incidence and causes of non-invasive mechanical ventilation failure after initial success. Thorax 2000;55:819-25.

11. National Institutes of Health and Clinical Excellence. Chronic obstructive pulmonary disease, Clinical Guideline 2010. Management of chronic obstructive pulmonary disease in adults in primary and secondary care. Available from: http://www.nice.org.uk/nicemedia/live/13029/49399/49399.pdf
12. Chiumello D, Conti G, Foti G, et al. Noninvasive ventilation outside the Intensive Care Unit for acute respiratory failure. Minerva Anestesiol 2009;75:459-66.

13. Balami JS, Packham SM, Gosney MA. Non-invasive ventilation for respiratory failure due to acute exacerbations of chronic obstructive pulmonary disease in older patients. Age Ageing 2006;35:75-8.

14. Fiorino S, Detotto E, Battilana M, et al. Severe exacerbations of chronic obstructive pulmonary disease: management with noninvasive ventilation on a general medicine ward. Italian J Med 2010;4:173-8.

15. O'Driscoll BR, Howard LS, Davison AG; British Thoracic Society. BTS guideline for emergency oxygen use in adult patients. Thorax 2008;63:vi1-68.

16. Plant PK, Owen JL, Elliott MW. Early use of non-invasive ventilation for acute exacerbations of chronic obstructive pulmonary disease on general respiratory wards: a multicentre randomised controlled trial. Lancet 2000;355:1931-5.

17. Collaborative Research Group of Noninvasive Mechanical Ventilation for Chronic Obstructive Pulmonary Disease. Early use of noninvasive positive pressure ventilation for acute exacerbations of chronic obstructive pulmonary disease: a multicentre randomized controlled trial. Chin Med J 2005;118;2034-40.

18. Cabrini L, Idone C, Colombo S, et al. Medical emergency team and non invasive ventilation outside ICU for acute respiratory failure. Intensive Care Med 2009;35:339-43.

19. Scarpazza P, Incorvaia C, di Franco G, et al. Effect of noninvasive mechanical ventilation in elderly patients with hypercapnic acute-on-chronic respiratory failure and a do-not-intubate order. Int J Chron Obstruct Pulmon Dis 2008;3:797-801. 